\title{
Estudo do Perfil Etiológico da Meningite Bacteriana no Estado do Tocantins
}

\section{Study of the Etiological Profile of Bacterial Meningitis in the State of Tocantins}

Mohanna Damasceno Arbués'; Victor Rodrigues Nepomuceno; Tiago Veloso

Neves 3 ; Poliana Guerino Marson ${ }^{4}$.

\section{RESUMO}

Objetivo: analisar o perfil etiológico da meningite bacteriana no estado do Tocantins. Métodos: estudo retrospectivo, transversal, de natureza quantitativa, realizado através de levantamento de dados provenientes do Laboratório Central de Saúde Pública do Estado do Tocantins (LACEN-TO), no período de 2010 a 2017, em relação à realização de culturas de líquido cefalorraquidiano (LCR) para o diagnóstico laboratorial de meningite bacteriana. Resultados: foram realizadas 2041 culturas de LCR, havendo um baixo crescimento bacteriano. O grupo bacteriano com maior crescimento dentre as culturas positivas foi o dos Staphylococcus coagulase negativos (SCN), principalmente ○ $S$. epidermides. Dentre as bactérias de importância a saúde pública, a de maior incidência foi Streptococcus pneumoniae (sorotipo 3 e 19A), acometendo consideravelmente indivíduos do sexo masculino e abaixo de 60 anos. Conclusão: o principal agente etiológico da meningite bacteriana no estado do Tocantins, de importância à saúde pública, no período estudado foi o $S$. pneumoniae. Destaca-se a multirresistência aos antibióticos apresentada pelo S. pneumoniae sorotipo $19 \mathrm{~A}$.

Palavras-chave: Líquido cefalorraquidiano. Streptococcus pneumoniae. Diagnóstico laboratorial.

\section{ABSTRACT}

Objective: to analyze the etiological profile of bacterial meningitis in the state of Tocantins. Methods: it was a retrospective, cross-sectional study of a quantitative nature, carried out through data collection from the Central Laboratory of Public Health of the State of Tocantins (LACEN-TO), from 2010 to 2017, in relation to cerebrospinal fluid (CSF) for the laboratory diagnosis of bacterial meningitis. Results: 2041 CSF cultures were performed, with low bacterial growth. The bacterial group with the highest growth among the positive cultures was the coagulase negative Staphylococcus (SCN), mainly $S$. epidermides. Among the bacteria of public health importance, the one with the highest incidence was Streptococcus pneumoniae (serotype 3 and 19A), considerably affecting males and under 60 years. Conclusion: The main etiological agent of bacterial meningitis in the State of Tocantins, of importance to public health, during the period studied was $S$. pneumoniae. We highlight the multiresistance of antibiotics presented by S. pneumoniae serotype 19A.

Keywords: Cerebrospinal fluid. Streptococcus pneumoniae. Laboratory diagnosis. 


\section{INTRODUÇÄO}

A meningite é definida como um processo inflamatório das meninges, membranas que envolvem o cérebro, que progressivamente causa danos ao sistema nervoso central (SNC), podendo levar o indivíduo a óbito rapidamente (KONEMAN, 2008). Sua etiologia é variada, sendo que as mais conhecidas e severas pertencem ao grupo das meningites bacterianas, onde os principais agentes, em 90\% dos casos, são: Streptococcus pneumoniae, Neisseria meningitidis e Haemophilus influenzae (BRASIL, 2017; FARHAT, 1999).

A meningite bacteriana é caracterizada por ser uma doença infectocontagiosa, sendo transmitida pelo contato íntimo prolongado com os portadores das bactérias através de aerossóis, constituindo um sério problema de saúde pública. Mesmo com advento de vacinações, avanços nos métodos diagnósticos, tratamento antimicrobiano e de suporte à vida, tem apresentado altos índices de mortalidade (BROWER, 2010).

O diagnóstico da meningite bacteriana é realizado pela avaliação clínica caracterizada por febre, cefaleia intensa, rigidez de nuca, fotofobia, letargia, vômitos e sinais de irritação meníngea (sinal de Kerning e sinal de Brudzinski), acompanhadas de alterações do líquido cefalorraquidiano (LCR), que são avaliadas laboratorialmente e inclui avaliação quimiocitológica, cultura-teste de sensibilidade a antimicrobianos (TSA) e teste de látex específico para detecção dos antígenos dos principais agentes (COMAR et al., 2009; KONEMAN, 2008).

Atualmente, a técnica de reação em cadeia da polimerase (PCR) e suas variações, pode ser utilizada na identificação do agente etiológico, porém, ainda possui custo relativamente alto e seu uso ainda está restrito a grandes centros de pesquisas (SALGADO et al., 2013). A técnica de biologia molecular possui vantagens por ser um método rápido, fidedigno e que não é afetado pelo uso prévio de antibiótico, interferentes da coleta ou processamento tardio do LCR, demonstrando alta sensibilidade e especificidade (CORLESS et al., 2001; TAHA, 2000).

A meningite bacteriana é uma doença geralmente de progressão rápida, sendo inviável a espera do diagnóstico laboratorial, por meio de cultura e TSA, pois pode perdurar até 10 dias para serem liberados e, assim iniciar o tratamento, sendo este, portanto, primeiramente realizado de forma empírica, o que pode levar a consequências danosas ao paciente, como falha terapêutica e resistência a antimicrobianos por parte dessas bactérias (BRASIL, 2017; KONEMAN, 2008).

No estado do Tocantins não há estudo sobre quais os principais agentes etiológicos e seus sorotipos circulantes causaram meningites na população. Sendo assim, o 
levantamento das principais bactérias causadoras de meningite bacteriana torna-se importante, pois nos possibilita o conhecimento da realidade estadual, e consequentemente o ajuste adequado dos protocolos a serem seguidos em termos de suporte à vida e tratamento mais assertivo estabelecido nos indivíduos acometidos.

Por serem inéditos, os dados obtidos nesse estudo poderão fomentar o desenvolvimento de ações de vigilância mais adequadas à realidade existente e contribuir para o uso mais adequado da antibioticoterapia, o que acarretará em maior possibilidade de sucesso terapêutico, assim como, diminuir a resistência antimicrobiana e o aparecimento de bactérias multirresistentes, foco de grande preocupação, uma vez que representam um dos mais graves desafios atuais de saúde pública.

\section{METODOLOGIA}

Foi realizado um estudo retrospectivo, transversal, de natureza quantitativa através de análise de laudos e relatórios de culturas de LCR de pacientes com suspeita de meningite bacteriana atendidos pela Secretaria de Saúde do Tocantins (SESAU-TO), através do Laboratório Central de Saúde Pública do Estado do Tocantins (LACEN-TO), no período compreendido entre 2010 a 2017.

O período de estudo foi delimitado devido ao ano de implantação do sistema de informação utilizado no LACEN-TO, datado no ano de 2010 e denominado Gerenciador de Ambiente Laboratorial (GAL).

A coleta dos dados foi obtida através do GAL, porém é importante ressaltar que as etapas do diagnóstico laboratorial da meningite no Tocantins não são de responsabilidade exclusiva do LACEN-TO, sendo que outras instituições e profissionais estão envolvidos, tornando-se um complexo fluxo, conforme apresentado na figura 1.

Os critérios de inclusão adotados foram laudos completos, contendo todas as informações pertinentes à pesquisa, evidenciando se o paciente era residente no estado do Tocantins. Enquanto que os critérios de exclusão foram os laudos de pacientes diagnosticados no Tocantins, porém residentes de outros estados.

As variáveis analisadas nos laudos e relatórios de pacientes foram: faixa etária, sexo e agente etiológico. 


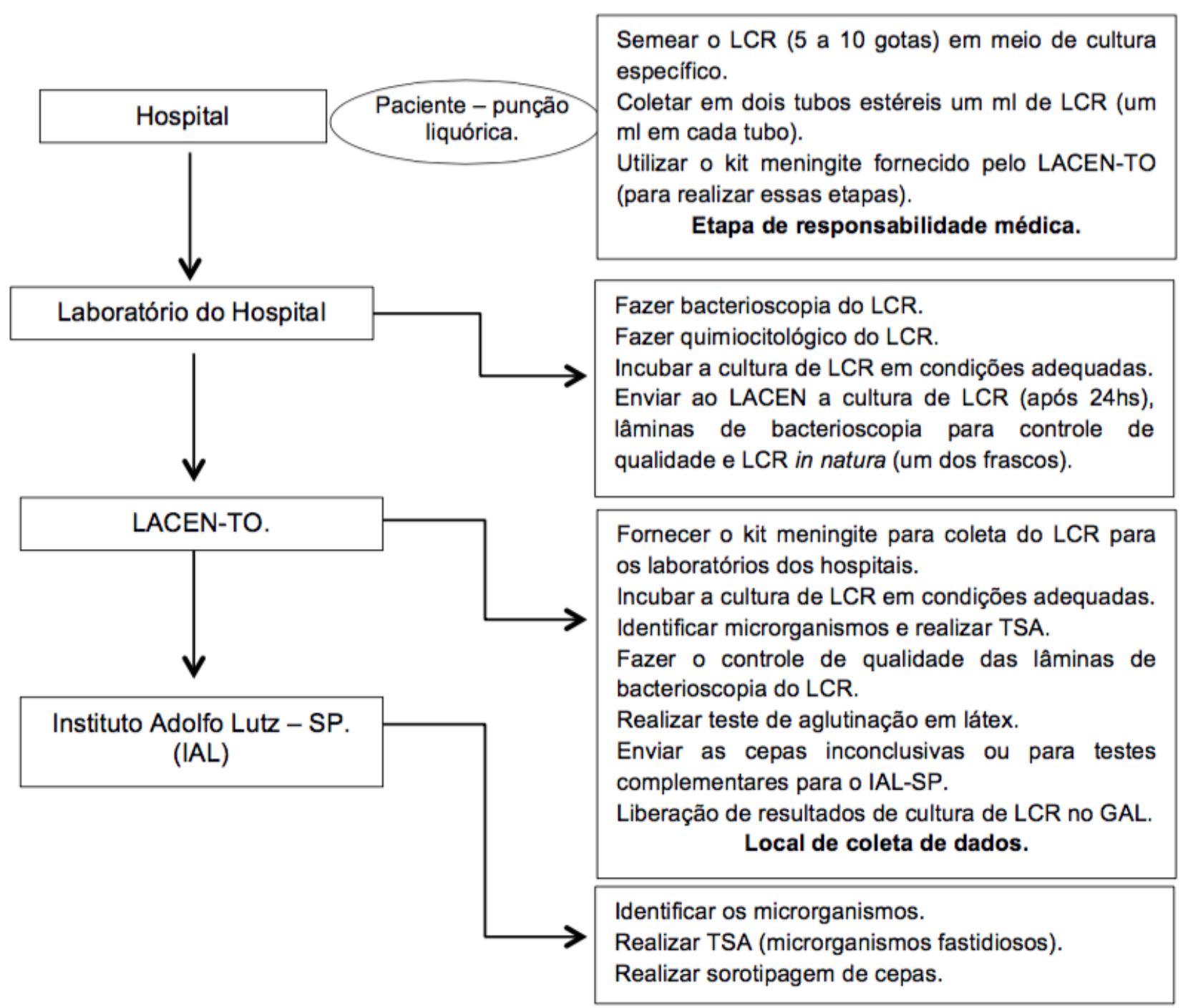

Figura 1. Fluxograma do diagnóstico laboratorial da meningite bacteriana no Tocantins.

Para o processamento de dados, os mesmos foram digitalizados em planilhas no Microsoft Excel e visualmente representados por gráficos e tabelas. A análise estatística dos dados obtidos foi realizada utilizando os pacotes estatísticos Bioestat 5.0 e Epi-info 7.0, tendo sido utilizado o teste de qui-quadrado. Foi considerado significativo um valor de $p<0,05$.

Todos os aspectos éticos no qual trata a Resolução 466/12 do Conselho Nacional de Saúde (CNS), pela qual pertence este tipo de estudo, foram devidamente respeitados, tendo aprovação pelo Comitê de Ética em Pesquisa (CEP) da Universidade Federal do Tocantins (UFT) conforme parecer de nº. 2.292.448, emitido em 22 de setembro de 2017. 


\section{RESULTADOS}

Através do levantamento de dados constatou-se que foram realizadas 2041 culturas de LCR para diagnóstico de meningite bacteriana pelo LACEN-TO, referência estadual no diagnóstico laboratorial deste agravo.

Na figura 2, observa-se que houve aumento do número de culturas de LCR ao longo do período analisado e elevado número de culturas de LCR negativas, principalmente no período de 2016/2017.

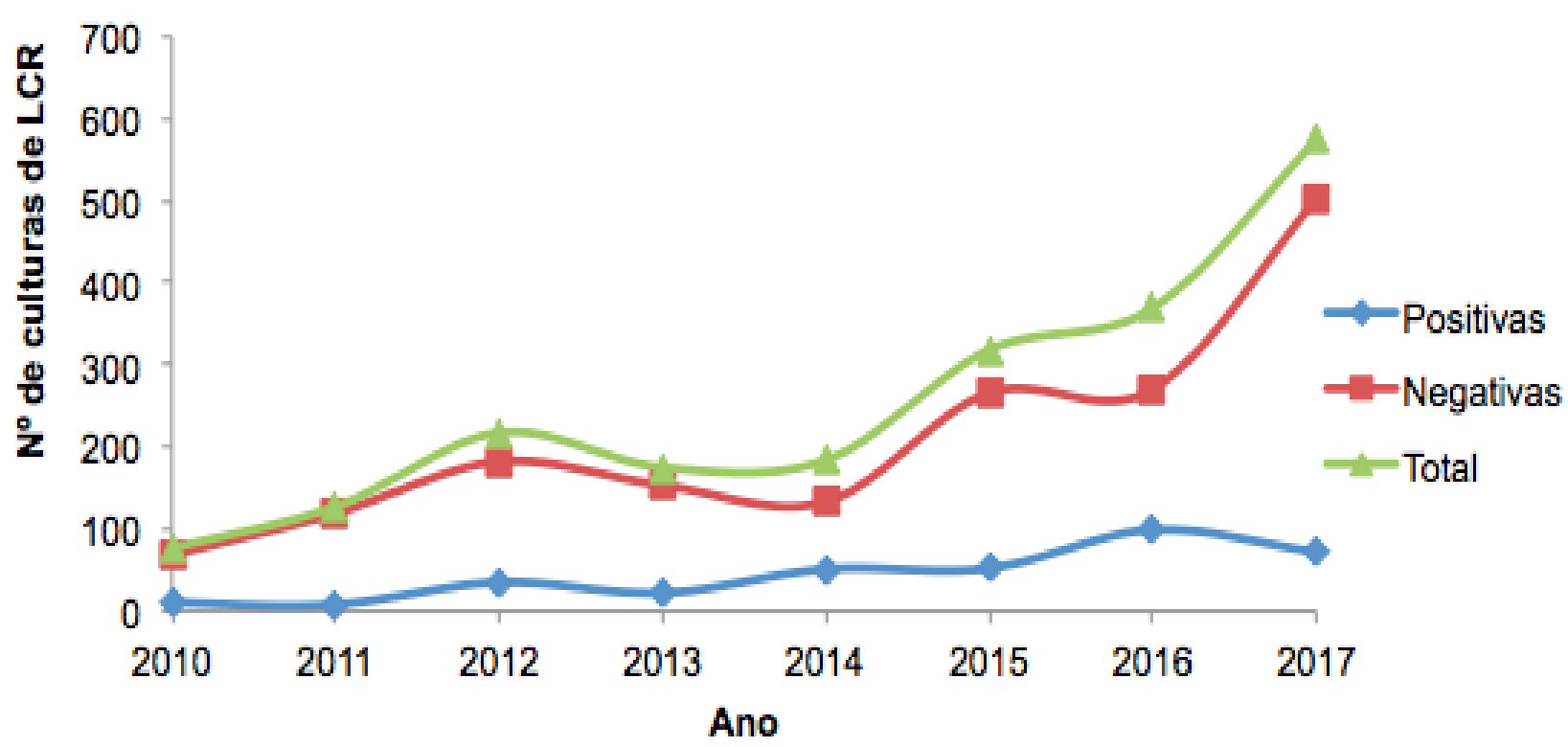

Figura 2 . Culturas de LCR realizadas de 2010 a 2017.

Conforme tabela 1, dentre as culturas de LCR positivas, os principais microrganismos isolados foram o grupo Staphyloccoccus coagulase negativos (27,3\%), seguidos pela somatória de diversos microrganismos diferentes, incluindo fungos (22,7\%). Observa-se também, um isolamento baixo de bactérias fastidiosas, grupo que engloba as bactérias de importância à saúde pública $(H$. influenzae, $S$. pneumoniae e $N$. meningitidis) para meningite bacteriana $(6,7 \%)$. 
Tabela 1. Microrganismos isolados em culturas de LCR de 2010 a 2017.

\begin{tabular}{lccccccccr}
\hline & \multicolumn{10}{c}{ ANO } \\
Microrganismo & $\mathbf{2 0 1 0}$ & $\mathbf{2 0 1 1}$ & $\mathbf{2 0 1 2}$ & $\mathbf{2 0 1 3}$ & $\mathbf{2 0 1 4}$ & $\mathbf{2 0 1 5}$ & $\mathbf{2 0 1 6}$ & $\mathbf{2 0 1 7}$ & \multicolumn{1}{c}{$\%$ (total) } \\
\hline S. pn. & 2 & 2 & 5 & 1 & 3 & 2 & 1 & 3 & $5,8 \%(19)$ \\
N. $\boldsymbol{m}$. & 0 & 0 & 2 & 0 & 0 & 0 & 0 & 0 & $0,6 \%(2)$ \\
H. . & 0 & 0 & 0 & 0 & 0 & 0 & 0 & 1 & $0,3 \%(1)$ \\
S. cn & 2 & 2 & 4 & 6 & 15 & 19 & 23 & 19 & $27,3 \%(90)$ \\
BGNNF & 1 & 0 & 5 & 4 & 12 & 6 & 19 & 10 & $17,3 \%(57)$ \\
Enterobac. & 1 & 1 & 2 & 1 & 7 & 8 & 2 & 13 & $10,6 \%(35)$ \\
S. aureus & 2 & 0 & 3 & 1 & 2 & 0 & 6 & 0 & $4,2 \%(14)$ \\
BGP & 1 & 0 & 2 & 3 & 0 & 0 & 16 & 1 & $7 \%(23)$ \\
E. ssp & 1 & 0 & 0 & 0 & 0 & 3 & 0 & 4 & $2,4 \%(8)$ \\
MO ni & 0 & 0 & 1 & 0 & 2 & 1 & 1 & 1 & $1,8 \%(6)$ \\
MO outros & 0 & 1 & 6 & 2 & 4 & 5 & 6 & 5 & $22,7 \%(75)$ \\
\hline
\end{tabular}

Legenda: S.pn.: Streptococcus pneumoniae; N. m.: Neisseria meningitides; H. i.: Haemophilus influenzae; S. cn: Staphylococcus coagulase negativo; BGNNF: Bacilos Gram negativo não fermentadores; Enterobac.: Enterobactérias; E. ssp: Enterococcus spp; BGP: Bacilos Gram positivo; MO ni: microrganismos não identificados; MO outros: outros microrganismos.

Ainda, em relação aos microrganismos fastidiosos, houve um predomínio de $S$. pneumoniae, em todo período estudado, sendo que em todos os anos houve sua ocorrência (figura 3).

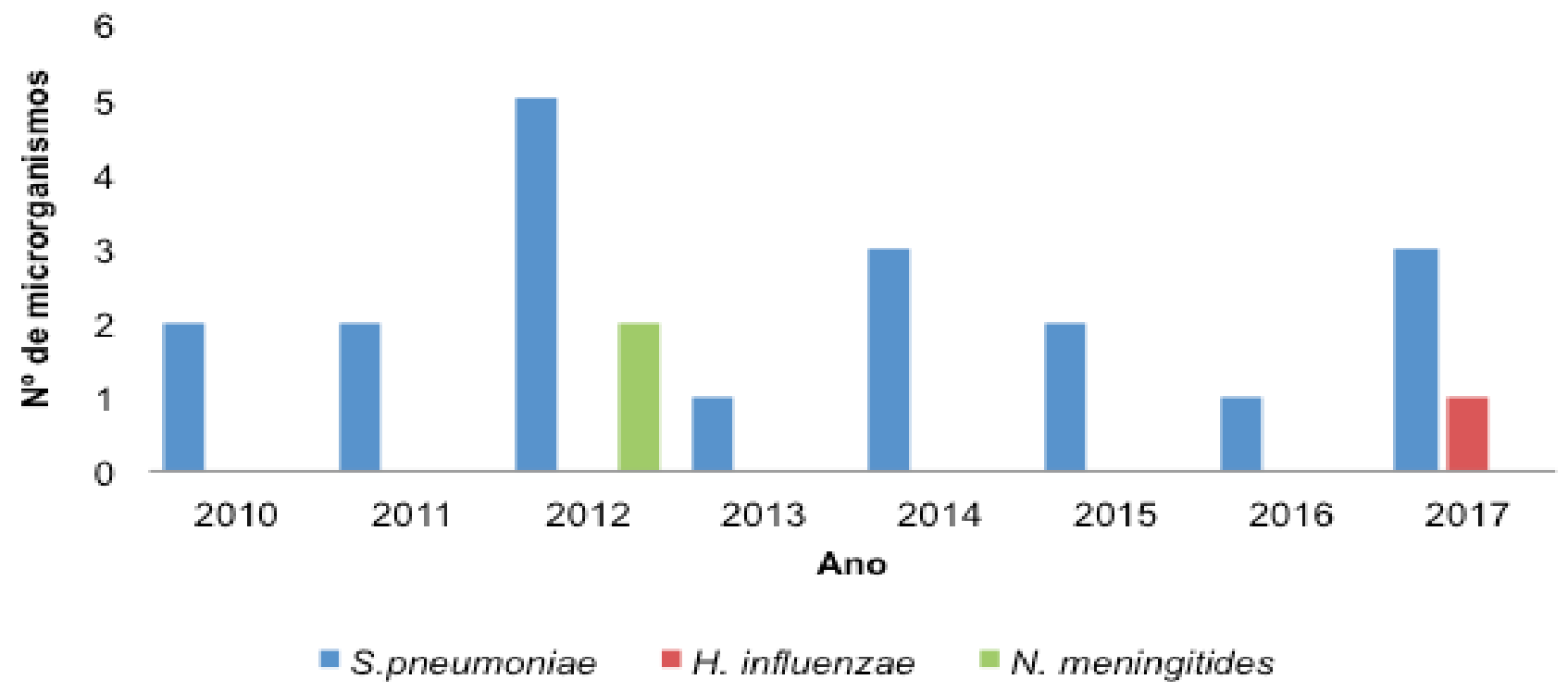

Figura 3. Microrganismos fastidiosos em culturas de LCR de 2010 a 2017.

As faixas etárias mais comprometidas foram as abaixo de 60 anos, não havendo diferença entre as faixas de crianças, adolescentes e adultos, tendo prevalência o sexo 
masculino, onde foi encontrada uma associação estatisticamente significativa entre agente etiológico e sexo $(p<0,05)$, conforme tabela 2.

Tabela 2. Distribuição de S. pneumoniae por faixa etária e sexo.

\begin{tabular}{ccc}
\hline & \multicolumn{2}{l}{ S. pneumoniae } \\
(anos)/sexo & F & M \\
\cline { 2 - 3 } & 0 & 6 \\
$\mathbf{0 - 1 5}$ & 1 & 4 \\
$\mathbf{1 6 - 2 9}$ & 3 & 4 \\
$\mathbf{3 0 - 5 9}$ & 0 & 1 \\
Acima de 60 & 4 & 15 \\
Total & & 19 \\
\hline Total geral & & \\
\hline
\end{tabular}

Legenda: F: feminino; M: masculino.

Em relação aos sorogrupos e sorotipos prevalentes, foi identificado o predomínio dos sorotipos 3 e 19A para $S$. pneumoniae, o sorogrupo $\mathrm{C}$ para $N$. meningitidis e para $H$. influenzae foi o sorotipo $b$.

Ainda, como resultado importante a ser ressaltado no presente estudo, foi o predomínio de Staphylococcus epidermidis, dentre o grupo de Staphyloccocus coagulase negativos, observado na figura 4.

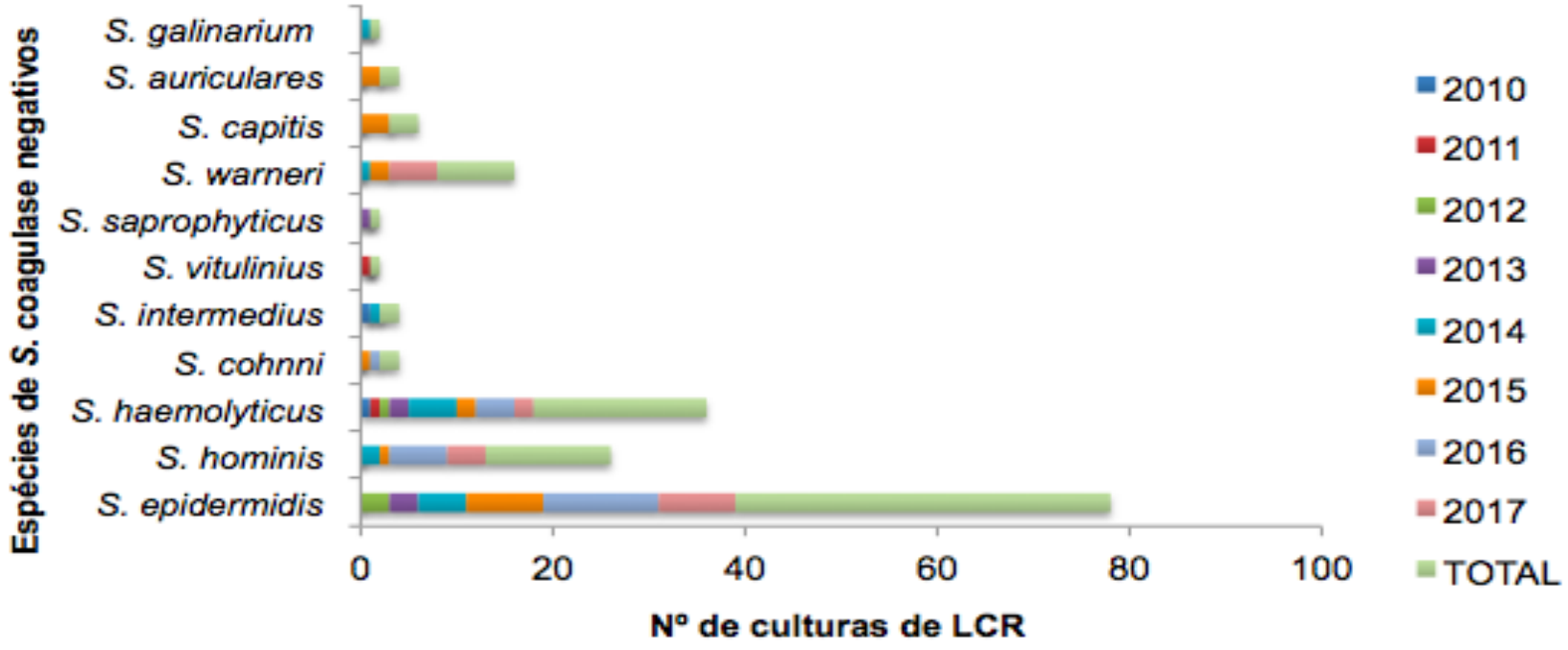

Figura 4. Espécies de Staphyloccocus coagulase negativos em culturas de LCR. 
A tabela 3 mostra os resultados dos TSAs realizados nos sorotipos encontrados para S. pneumoniae.

Tabela 3. Resultados de TSA de sorotipos de cepas de S. pneumoniae de 2010 a 2017.

\begin{tabular}{lccccccccccc}
\hline ANO & \multicolumn{2}{c}{2010} & 2011 & \multicolumn{9}{c}{2012} & \multicolumn{9}{c}{2014} & 2015 & \multicolumn{2}{c}{2017} \\
\multicolumn{1}{c}{ ANTIB. } & 6A & 23F & 11A & 9V & 18B & 6C & 5 & 35F & 3 & 19A & 3 \\
\hline CLO & S & S & S & S & S & S & S & S & S & S & S \\
ERI & S & S & S & S & S & S & S & S & S & R & S \\
SUT & R & R & S & S & S & S & S & I & S & R & S \\
VAN & S & S & S & S & S & S & S & S & S & S & S \\
CLI & S & S & S & S & S & S & S & S & S & S & S \\
LEV & S & S & S & S & S & S & S & S & S & S & S \\
RIF & S & S & S & S & S & S & S & S & S & S & S \\
TET & S & S & S & S & S & R & I & S & S & R & S \\
CEF & NT & NT & NT & NT & NT & NT & NT & S & NT & I & NT \\
PEN & NT & NT & NT & NT & NT & NT & NT & R & NT & R & NT \\
\hline
\end{tabular}

Legenda: ANTIB.: Antibiótico; CLO: Clorofenicol; ERI: Eritromicina; SUT: Sulfametaxazol/Trimetropim; VAN: Vancomicina; CLI: Clindamicina; LEV: Levofloxacina; RIF: Rifampicina; TET: tetraciclina; PEN: Penicilina; CEF: Ceftriaxona; S: Sensível; I: Intermediário; R: Resistente; NT: Não testado.

Observa-se que o sorotipo mais prevalente, 3 , e os sorotipos $11 \mathrm{~A}, 9 \mathrm{~V}$ e $18 \mathrm{~B}$, apresentaram-se sensíveis a todos os antibióticos testados, portanto, provavelmente ainda não apresentam resistência intrínseca aos antibióticos comumente utilizados em sua terapia. Em contrapartida, entre todos os sorotipos, o 19A, foi o que apresentou resistência a um maior número de antimicrobianos, sendo eles: eritromicina, penicilina, sulfametaxazo//trimepetropim e tetraciclina, apresentando-se também com sensibilidade intermediária a ceftriaxona. Alguns outros sorotipos, como 6A, 23F, 6C, 5 e 35F, apresentaram resistência a sulfametaxazol/trimetropim (27\%), tetraciclina (18\%) e eritromicina (9\%); não houve casos de sorotipos com resistência à vancomicina.

\section{DISCUSSÃO}

O aumento do número de culturas realizadas durante o período analisado pode ser justificado pelo aumento demográfico do estado, haja visto que no ano de 2010 a população era de 1.383.445 habitantes e a estimativa para o ano de 2018 é de 1.555.229 habitantes (IBGE, 2018). Assim como, podem ter havido melhorias no diagnóstico clínico da meningite bacteriana e, portanto, maior número de coletas de LCR e realização de culturas, uma vez que o LACEN-TO promove capacitação aos profissionais envolvidos constantemente. 
Além desses fatores, deve ser incluído, em associação, um possível aumento de casos de meningite bacteriana ao longo do período analisado.

No contexto do expressivo número de culturas negativas, é possível que alguns fatores comprometam o crescimento bacteriano, principalmente para os microrganismos fastidiosos, assim denominados, devido sua exigência nutricional e atmosférica para crescimento. Os principais agentes etiológicos da meningite são considerados fastidiosos, uma vez que, necessitam para seu crescimento em cultura, condições apropriadas, tais como, meios de cultura enriquecidos, atmosfera com baixas tensões de oxigênio e com umidade, temperatura adequada para crescimento $\left(35^{\circ} \mathrm{C}+/-2^{\circ} \mathrm{C}\right)$, pois são sensíveis a baixas temperaturas, condições adequadas de transporte, entre outras exigências (OPLUSTIL et al., 2010). As primeiras análises devem efetuadas idealmente em até 2 horas após a coleta, sendo que a positividade para culturas de LCR começam a sofrer alterações, caso não sejam devidamente processadas em até 15 minutos, devido a brusca diminuição da viabilidade dos seus principais agentes etiológicos: $H$. influenzae, $S$. pneumoniae e $N$. meningitidis (THOMSON; MILLER, 2003).

Desta forma, é orientado que imediatamente após a coleta do material, realizado exclusivamente por profissional médico, esse realize o semeio do LCR em meio adequado e de maneira asséptica, seguindo as normas de biossegurança (BRASIL, 2017).

Ressalta-se que o LACEN-TO é apenas parte das instituições envolvidas no processo de diagnóstico da meningite bacteriana, sendo que o mesmo dá continuidade aos procedimentos laboratoriais, das amostras de culturas de LCR, recebidas das unidades de saúde, ficando sob sua responsabilidade identificar os microrganismos e realizar TSA dessas culturas e/ou enviar para o laboratório de referência nacional, Instituto Adolfo Lutz (IAL) em São Paulo (SP), para análises complementares como sorotipagem e TSA (quando não realizados pelo LACEN-TO). Os laboratórios locais que atendem aos hospitais, onde são realizadas as punções liquóricas, sejam eles públicos ou particulares, são responsáveis pelas primeiras análises do LCR, conforme apresentado na figura 1 .

Ainda nesse contexto, o LACEN-TO, como todo laboratório central de saúde pública, possui protocolos operacionais padrões e controle de qualidade interno e externo, para garantir a qualidade do que é de sua responsabilidade dentro do diagnóstico da meningite bacteriana. Além disso, também promove capacitações juntamente com a vigilância epidemiológica do estado, para os laboratórios envolvidos e para os médicos, seguindo todas as normativas preconizadas pelo Ministério da Saúde (MS), na tentativa de uniformizar os serviços e melhorar o cenário no diagnóstico da meningite bacteriana no 
estado, como citado anteriormente, esse fato que pode ter gerado melhoria ao longo do período analisado, para o diagnóstico da meningite bacteriana no estado. Entretanto, a complexidade e diversidade de responsabilidades nas etapas podem estar relacionadas à baixa positividade dessas culturas de LCR. Sendo assim, é fundamental que todos os profissionais envolvidos estejam alinhados e que haja entendimento que o sucesso do diagnóstico começa desde a primeira etapa do processo, que é a coleta e seus procedimentos iniciais.

Outro fator de extrema importância no sucesso desse diagnóstico, é que a punção seja realizada antes da administração de antibióticos. É preconizado pelo Guia de Vigilância do Ministério da Saúde, que a coleta seja realizada, se possível, antes da adoção da antibioticoterapia (BRASIL, 2017). A rápida progressão da meningite, muitas vezes, faz com que a conduta clínica seja adotar antibioticoterapia imediatamente, entretanto se a punção for realizada depois, a sensibilidade do método pode diminuir drasticamente. Este é outro fator que poderia justificar a baixa positividade total das culturas de LCR no presente estudo. Corrobora com esse fato, Mantese et al. (2002), que relatam uma diminuição da positividade da cultura de LCR de $71,7 \%$ para $57,6 \%$ devido a introdução da antibioticoterapia prévia a punção. Mais uma vez, ressalta-se a importância do diálogo e entendimento entre a equipe clínica e a equipe laboratorial para o sucesso do diagnóstico, assim como é fundamental que nas unidades emergências de saúde, existam profissionais médicos capacitados para os procedimentos adequados da coleta de LCR.

Avaliando o montante geral de culturas positivas e seus respectivos agentes etiológicos (tabela 1), observa-se que o grupo predominante foi o Staphylococcus coagulase negativos $(27,3 \%)$, o que sugere provável contaminação no ato da punção de LCR, uma vez que dentro deste grupo o microrganismo mais prevalente foi 0 Staphylococcus epidermidis (figura 4), sendo que o mesmo faz parte da microbiota da pele e mucosas, possuindo baixa correlação com a meningite bacteriana, apesar de alguns autores como Ferreira e Moraes (2017) relatarem meningite por essa bactéria em pacientes hospitalizados que utilizam dispositivos médicos, graças à capacidade dessas bactérias de produzirem uma substância polissacarídica viscosa chamada slime, um fator de virulência importante para este grupo bacteriano, que favorece aderência nesses dispositivos hospitalares (FERREIRA; MORAES, 2017). Dessa maneira, podem vir a causar infecções locais ou sistêmicas (OPLUSTIL et al., 2010; MILLER; JULBERT, 2002). E, portanto, nessas situações podem também vir a provocar meningite bacteriana, porém não por via comunitária, e sim por acesso através de dispositivos hospitalares, sendo necessária 
avaliação médica do paciente para confirmar a possibilidade deste tipo de infecção por esta bactéria. Nesse contexto, destaca-se, portanto, à fragilidade na realização dos processos de coleta e cultura desse agravo, sendo imprescindível que os procedimentos realizados pelas equipes médicas sejam rigorosamente controlados, inclusive, justificando, que em toda unidade de saúde haja protocolos operacionais padrões para diminuir possíveis problemas vinculados a essa situação, o que não é pertinente a realidade local.

Em relação aos microrganismos fastidiosos observa-se que houve um predomínio de S. pneumoniae, sendo que em todos os anos houve sua ocorrência (figura 3). Não foi encontrado nenhum marco circunstancial ou temporal para justificar o aparecimento dos episódios da etiologia do meningococo (2012) e H. influenzae (2017), porém é conhecido que esses dois microrganismos são mais fastidiosos, quando comparados ao pneumococo, que consegue ser menos sensível a condições de crescimento in vitro, ao conseguir crescer em meios de cultura menos complexos, como ágar sangue e, portanto, possuem taxa maior de sensibilidade para o seu isolamento em cultura. Contudo, isso deve ser melhor avaliado em estudos futuros que consigam comparar a cultura de LCR com testes menos sensíveis as condições de amostra e exames laboratoriais, como as técnicas de biologia molecular.

Apesar do baixo crescimento das bactérias fastidiosas no presente estudo, é relevante destacar, a importância dessas bactérias, uma vez que em estudo de Dias et al. (2017) comprovaram que a taxa de letalidade para este grupo bacteriano atinge $12,81 \%$ na região Norte do Brasil, e portanto, é preocupante, para o cenário da saúde pública, pois essas cepas configuram um poder de patogenicidade elevado e mesmo com os avanços em terapias de suporte, apresentam esse índice.

O S. pneumoniae, microrganismo mais representativo dentre os microrganismos fastidiosos, acometeu mais indivíduos do sexo masculino, (tabela 2). Segundo Klein e Marcy (1983), esse fato parece ter correlação a uma participação de base genética, ligada ao cromossomo específico, na propensão ao desenvolvimento de infecções, mas outros fatores devem estar associados, entretanto ainda não estão totalmente elucidados.

Dados semelhantes a essa pesquisa foram relatados por Almeida et al. (2016), em pacientes do Hospital de Clínicas da Universidade Federal do Paraná, onde o principal agente da meningite foi o $S$. pneumoniae (8,7\% dos casos), corroborando também com o baixo percentual de crescimento em cultura (presente estudo 5,8\%), demonstrando mais uma vez, a dificuldade de crescimento dessas bactérias laboratorialmente. De forma semelhante, Dias et al. (2017), em estudo abrangendo a região Norte do Brasil, relatam que o perfil etiológico, sexo e faixa etária, corroboram com o presente estudo, mostrando que a 
caracterização da realidade tocantinense, se estende a sua própria região. Porém, no estudo de Dias et al. (2017), houve constatação de diminuição do número de casos de meningite na região Norte, fato contrário a realidade do Tocantins detectada na presente pesquisa, onde ao decorrer dos anos houve um aumento no número de culturas de LCR, pressupondo-se que houve um aumento do número de casos, conforme apresentado na figura 2. Entretanto a base de dados desses autores foi o sistema de informação de agravos de notificação (SINAN), que é totalmente dependente de notificação, considerando que esse agravo há muito problema de subnotificação, esses dados podem não demonstrar a real situação regional.

Em relação ao perfil de sensibilidade a antimicrobianos apresentadas pelas cepas de pneumococo, em estudo realizado no sul do Brasil (DULLIUS; ZANI; CHATKIN, 2018), onde os principais sorotipos encontrados também foram o 3 e 19A, observou-se uma taxa de resistência a sulfametaxazol/trimetropim de 37,3\%, a eritromicina de 17,8\% e a penicilina de $9,3 \%$, o que evidencia a resistência bacteriana a diferentes classes de antimicrobianos, fato esse que é agravado quando se pratica terapias empíricas. Outro estudo de Weil e Gaillat (2014), relata que o sorotipo 14 é o mais frequente no Brasil, enquanto os menos frequentes são $23 \mathrm{~A}, 35 \mathrm{~F}$ e 35B e que os sorotipos $6 \mathrm{~A}, 6 \mathrm{~B}, 19 \mathrm{~F}, 23 \mathrm{~F}, 8,6 \mathrm{C}$ e 3 estão relacionados as maiores taxas de mortalidade. Vale destacar a importância da definição de sorogrupos e sorotipos para microrganismos como pneumococo, pois como tem sido apresentado, existem alguns tipos que configuram maior virulência e podem apresentar resistência a determinadas classes de antimicrobianos. Além disso, quando são identificados esses parâmetros, consegue-se avaliar a eficácia do emprego de vacinas utilizadas ou até mesmo a necessidade do desenvolvimento de outras com novas valências.

Em estudo de Medeiros et al. (2017), os sorotipos de $S$. pneumoniae mais resistentes à penicilina foram 9V, 14, 19A e 23F, enquanto os mais susceptíveis foram o $7 \mathrm{~F}, 1,12 \mathrm{~F}$, 18C, 3, 4 e 5. Correlacionando com o presente estudo, observa-se o mesmo perfil, onde o sorotipo 3 possui alto índice de susceptibilidade, enquanto que o sorotipo 19A apresentouse multirresistente. Ademais, a cepa de pneumococo sorotipo 19A, ainda apresentou resistência intermediária a ceftriaxona, o que pode prever um possível problema aos esquemas terapêuticos protocolados pelo MS, uma vez que este é o fármaco orientado para situações empíricas, caso haja uma tendência ao longo dos anos, de sorotipos como este circularem cada vez mais no país, o que aumenta a necessidade de contínuas ações de vigilância sobre os sorotipos/resistências apresentados, como foi realizado neste presente estudo. 
Pelos dados obtidos nesse estudo, pode-se sugerir que a melhor alternativa para o tratamento empírico dentro da realidade apresentada, é o uso de cefalosporina de terceira geração, como a ceftriaxona, podendo ser empregada nos agentes mais frequentemente isolados. Caso o paciente não apresente melhoria clínica, por poder se tratar de uma cepa como a sorotipo 19A (pneumococo), que já apresenta multirresistência, associações com vancomicina deverão ser feitas. Sendo que os ajustes farmacológicos devem ser realizados após resultado do TSA.

Deve se ressaltar que a importância do isolamento correto do agente etiológico nas culturas de LCR, contribui não apenas para o diagnóstico da doença, mas também para o tratamento mais adequado, a partir dos resultados do TSA, diminuindo a mortalidade, assim como, a redução do uso inadequado de antibióticos, que tem levado a resistência a antimicrobianos e o surgimento de cepas multirresistentes.

Além disso, é necessária a introdução de novas tecnologias na rotina para o diagnóstico laboratorial da meningite bacteriana, como a biologia molecular, que podem diminuir o tempo de diagnóstico e aumentar o conhecimento da etiologia deste agravo, devido sofrer menos influência em relação à qualidade da amostra, e pelo fato de não depender de cultivo de microrganismos, o que é complexo no caso deste agravo, devido seus agentes etiológicos serem de difícil crescimento em meio artificial.

\section{CONSIDERAÇÕES FINAIS}

O presente estudo relatou o perfil etiológico da meningite bacteriana no Tocantins nos anos de 2010 a 2017, onde o principal agente de importância a saúde pública foi o $S$. pneumoniae (sorotipo 3 e 19A), seguido por $N$. meningitidis (sorogrupo C) e $H$. influenzae (sorotipo b), sendo o sexo masculino o mais acometido e faixas etárias abaixo de 60 anos, não havendo distinção considerável entre crianças, adolescentes e adultos.

Apesar da maioria dos sorotipos de S. pneumoniae apresentarem susceptibilidade aos antibióticos, destaca-se a multirresistência aos antibióticos apresentada pelo $S$. pneumoniae sorotipo 19A.

Em relação ao diagnóstico laboratorial da meningite no estado do Tocantins, observase que a baixa positividade nas culturas, associado ao fato que o principal grupo de microrganismos foi Staphyloccocus coagulase negativo, sugerem a presença de fragilidade nesse processo, e demonstram que é imprescindível que haja melhorias no diagnóstico laboratorial da meningite, desde a punção, minimizando o crescimento de bactérias da microbiota nas culturas, à liberação de resultados. 


\section{REFERENCIAS}

ALMEIDA, B. M. et al. Interpretando o líquor - como dados epidemiológicos podem ajudar no raciocínio clinico. Revista Médica da UFPR. n. 1, v. 3, p. 13-18, 2016.

ANDRADE, A. L. et al. Population-based surveillance for invasive pneumococcal disease and pneumonia in infants and young children in Goiânia, Brazil. J. Vaccine. 30 (10). p. 19011909, 2012.

BRASIL. MINISTÉRIO DA SAÚDE. SECRETARIA DE VIGILÂNCIA EM SAÚDE. COORDENAÇÃO-GERAL DA EPIDEMIOLOGIA EM SERVIÇOS. Guia de Vigilância em Saúde. Vol. único / Ministério da Saúde, Secretaria de Vigilância em Saúde, Coordenaçãogeral da epidemiologia em serviços. 2. ed. Brasília: Ministério da Saúde, 705 p., 2017.

BROWER, M. C.; TUNKEL, A.R.; VAN DE BEEK, D. Epimemiology, diagnosis, and antimicrobial treatment of acute bacterial meningitis. Clin. Microbiol. Rev. v. 23, p. 467492, 2010.

COMAR, S. R. et al. Análise citológica do líquido cefalorraquidiano. Estud. Biol. v. 31, p. 93-102, 2009.

CORLESS, C.E. et al. Simultaneous detection of Neisseria meningitidis, Haemophilus influenzae and Streptococcus pneumoniae in suspected cases of meningitis and septicemia using real-time PCR. J Clin Microbiol. Apr; 39(4), p. 1553-1558, 2001.

DIAS, F. C. F. et al. Meningite: aspectos epidemiológicos da doença na região norte do Brasil. Revista de Patologia do Tocantins, v. 4., n. 2, p. 46-49, 2017.

DULLIUS, C.R; ZANI, L; CHATKIN, J.M.; Cobertura vacinal pneumocócica teórica: análise de sorotipos isolados de pacientes internados em hospital terciário. J. Brasileiro de Pneumologia. 2018. Ahead of print: 0-0.

FARHAT, C.K. Meningites bacterianas purulentas. In: Farhat CK, Carvalho ES, Carvalho LHFR, Succi RCM (eds). Infectologia Pediátrica. 2 ed. p. 89-103. São Paulo: Atheneu, 1999. FARIA, S.M.; FARHAT, C.K. Meningites bacterianas. J Pediatr. Rio de Janeiro. 75, p. 4656,1999 .

FERREIRA, A. W.; MORAES, S. L. Diagnóstico laboratorial das principais doenças infecciosas e autoimunes: correlação clínico-laboratoriais. 3 ed. Rio de Janeiro: Guanabara Koogan, 477p., 2017.

IBGE. Instituto Brasileiro de Geografia e Estatística (IBGE). Censo demográfico do Tocantins. Disponível em: <https://cidades.ibge.gov.br/brasil/to/panorama>. Acesso em: 09 set. 2018.

KLEIN, J. O.; MARCY, S. M.; Bacterial sepsis and meningitis. In: Remington J.S., Klein J.O. Infectious diseases of the fetus and newborn infant. 2 ed. Philadelphia: W B Saunders: p. $679-735,1983$.

KLIEGMAN, R. M. et al. Nelson tratado de pediatria. 20 ed. Rio de Janeiro: Elsevier, 2017. 
KONEMAN, Elmer W. Diagnóstico Microbiológico. In: Elmer W. Koneman. et. al. Introdução à microbiologia: Parte II: Indicações para colheita, transporte, processamento, análise e informe de cultivos obtidos a partir de amostras de fontes específicas. 5 ed. cap. 3, p. 125-176. Rio de Janeiro: Guanabara Koogan, 2008.

LEITE, C.R. et al. Clinical and bacteriological characteristics of invasive pneumococcal disease after pneumococcal 10-valent conjugate vaccine implementation in Salvador, Brazil. Braz J Infect Dis. 20(1), p. 56-60, 2016.

MANTESE, O. C. et al. Perfil etiológico das meningites bacterianas em crianças. Jornal de Pediatria. 78(6), p. 467-74, 2002.

MANTESE, O.C. et al. Prevalence of serotypes and antimicrobial resistance of invasive strains of pneumococcus in children: analysis of 9 years. J Pediatr. Rio de Janeiro. 85(6), p. 495-502, 2009.

MEDEIROS, M. I. C. et al. Antimicrobial susceptibility of Streptococcus pneumoniae isolated from patients in the northeastern macroregion of São Paulo state, Brazil, 1998-2013. Journal Bras. Patol. Med. Lab. v. 53, n. 3, p. 177-182, 2017.

MILLER, J. R.; JULBERT, B. Infecções bacterianas. In: ROWLAND, L. P. Merrit: Tratado de neurologia. 10. ed. cap. 21. Rio de Janeiro: Guanabara Koogan, p. 86-93, 2002.

MOTT, M. et al. Susceptibility profiles and correlation with pneumococcal serotypes soon after implementation of the 10-valent pneumococcal conjugate vaccine in Brazil. Int Journal Infect Dis, p. 47-51, 2014.

OPLUSTIL, C. P. et al. Procedimentos básicos em microbiologia clínica. 3. ed. São Paulo: Sarvier, 2010.

ROSSI, P. G, et al. Incidence of bacterial meningitis (2001-2005) in Lazio, Italy: the results of a integrated surveillance system. BMC Infectious Diseases, p. 9-13, 2009.

SALGADO, M. M. et al. Evolution of bacterial meningitis diagnosis in Sao Paulo State Brazil and future challenges. Arq. Neuro. Psiquiatric. 71 (9-B), p. 672-676, 2013.

TAHA, M.K. Simultaneous approach for nonculture PCR-based identification and serogroup prediction of Neisseria meningitidis. J Clin Microbiol. Feb. 38(2), p. 855-857, 2000.

THIGPEN, M. C. et al.; Bacterial meningitis in the United States, 1998-2007. The New England Journal of Medicine. May. 364, p. 2016- 2021, 2011.

THOMSON, RB; MILLER JM. Specimen collection, transport, and processing: bacteriology. In: Murray PR, Baron EJ, Jorgensen JH, Pfaller MA, Yolken RH, editors. Manual of Clinical Microbiology. Washington, p. 286-330, 2003.

VERANI, J.R., DOMINGUES, C.M., DE MORAES, J.C.; Brazilian pneumococcal conjugate vaccine effectiveness study group. Indirect cohort analysis of 10-valent pneumococcal conjugate vaccine effectiveness against vaccine-type and vaccine-related invasive pneumococcal disease. J. Vaccine. 33(46), p.6145-6148, 2015. 
WEIL-OLIVIER C., GAILLAT J. Can the success of pneumococcal conjugate vaccines for the prevention of pneumococcal diseases in children be extrapolated to adults? J. Vaccine. 32(18), p. 2022-2026, 2014. 